\title{
Synthesis of Nano - Nickel Metal Loaded on Faujasite-Zeolite for Reduction of p-nitro Phenol to p-amino Phenol
}

\author{
Amira M. Mahmoud ${ }^{1}$, Nadia A. Youssef', Seham A. Shaban², Mohamed M. Selim ${ }^{3 *}$ \\ ${ }^{1}$ Faculty of Girls, Ain Shams University, Cairo, Egypt. \\ ${ }^{2}$ Egyptian Petroleum Research Institute (EPRI), Cairo, Egypt. \\ ${ }^{3}$ National Research Center, Giza, Egypt.
}

\begin{abstract}
$\mathbf{N}$ ICKEL nanoparticles and $\mathrm{Ni}$ supported on faujasite- zeolite were prepared by using a solution of nickel nitrate of appropriate concentrations. The catalysts with 2.5, 5 and $10 \%$ nickel were reduced with hydrazine hydrate in the presence of alkali and used in reduction of p-nitrophenol to p- aminophenol. The prepared Ni catalysts were characterised by X-ray and SEM before and after conducting the reduction of p-nitrophenol. The results showed that catalysts contain nano nickel were durable in reduction of $\mathrm{p}$-nitro phenol to $\mathrm{p}$ - amino phenol. The Ni supported on faujasite-zeolite was more active than the unsupported Ni catalyst.
\end{abstract}

Keywords: Reduction, Nitrophenol, Aminophenol, Nanonickel.

\section{Introduction}

Recently, metal nano particles have been attracting great attention because of their remarkable catalytic performance in hydrogenation, oxidation and reduction reaction [1]. It was reported that $\mathrm{Pd}, \mathrm{Pt}, \mathrm{Rh}, \mathrm{Au}, \mathrm{Ru}$ and Ni nanoparticles exhibited higher catalytic activity than conventional supported metal catalysts in hydrogenation and oxidation reactions [2-3]. Nanoparticles exhibit a great variety of methods, such as wet chemical reduction in aqueous solution or in organic medium [7-8], microemulsion [9] and hydrothermal [1011] method. Among these preparation routes wet chemical reduction is a versatile and economic method. However, it is difficult to prepare phase pure nickel nanoparticles in aqueous medium because nickel nanoparticles are easily oxidized in water [12-13].

Zeolites have a well-defined nanopore structure with a crystalline framework. Zeolites can be used to load agents as well as to release them and the high ion-exchange capacity improves the loading of agents [14]. This particular pore architecture makes them suitable candidates for hosting and further delivering under appropriate conditions of a variety of molecules of pharmaceutical interest [15]. P-Aminophenol (PAP) is a commercially important intermediate for the manufacture of analgesic and antipyretic drugs [16]. Various methods have been reported to synthesize PAP, such as multi-step iron-acid reduction of p-nitrochlorobenzene or p-nitrophenol [2], catalytic hydrogenation of nitrobenzene [2-4], and an electrochemical synthesizing method [5]. The major disadvantage of iron-acid reduction is the generation of large amounts of $\mathrm{Fe}-\mathrm{FeO}$ sludge, which cannot be reused and causes severe disposal problems [4]. The catalytic hydrogenation of nitrobenzene in a strong acid aqueous medium is an important commercial method, but it also has two major drawbacks: (1) this reaction is complex and yields, in addition to the principal product, PAP, a significant amount of aniline and smaller amounts of other impurities [6];(2) the use of highly corrosive mineral acid. These disadvantages restrict production efficiency and product quality of PAP, and render those processes economically less attractive.

Our present work describes the synthesis of phase pure nickel nanoparticles via simple chemical reduction route starting from nickel nitrate and hydrazine hydrate in methanol. The prepared catalysts were characterized by scanning electron microscope and X-ray diffraction technique. The catalytic activity with and without support (zeolite) was conducted for reducing p-nitrophenol to p-amiophenol.

\section{Material and Methods}

Catalyst preparation.

Zeolite synthesis

Zeolite was prepared from Egyptian kaolin

*Corresponding author e-mail: mmaselim@yahoo.com 
by hydrothermal method according to Egyptian patent No. 23590.(2006).

The catalysts were prepared by impregnating the support (faujasite-zeolite) with appropriate quantities of $\mathrm{Ni}\left(\mathrm{NO}_{3}\right)_{2} \cdot 6 \mathrm{H}_{2} \mathrm{O}$ solution in order to obtain 2.5, 5 and $10 \mathrm{wt} . \%$ Ni on Zeolite.

\section{Characterization}

$X$-ray diffraction $(X R D)$

$X$-ray diffraction patterns were obtained using DrukerD8 advance instrument with $\mathrm{CuK} \alpha$ target with secondly monochromator $40 \mathrm{KV}, 40 \mathrm{~mA}$.

\section{Scanning Electron Microscopy}

The specimens were mounted on copper stubs with double-sides adhesive tape. The specimens were examined under JXA-840A Electron Probe Microanalyzer-JEOL-JAPAN.

\section{Reduction of the catalyst}

All the prepared solids were reduced by addition of hydrazine hydrate and few drops of concentrated sodium hydroxide and heating the mixture at 80 ${ }^{\circ} \mathrm{C}$ until the colour of the mixture turned to black or grayish black, indicating complete reduction of nickel ions into nanonickel metals.

\section{Reduction of p-nitrophenol.}

Dissolve $12.5 \mathrm{gm}$ of p-nitrophenol in $50 \mathrm{ml}$ methanol and add them in doses each of them is $5 \mathrm{ml}$ to the reduced catalyst under investigation followed by $10 \mathrm{ml}$ of hydrazine and few drops of $\mathrm{NaOH}$ solution. The mixture is heated until the colour is turned from yellow (p-nitrophenol) to colourless (p-aminophenol) indicating complete conversion. The complete reduction of p-nitrophenol into p-aminophenol was confirmed by using FTIR-spectroscopy, Figures 1 and 2 showed the FTIR of p-nitrophenol before reduction and the reduced $\mathrm{p}$-aminophenol after complete reduction. This experiment was don to confirm the complete conversion of $\mathrm{p}$-nitrophenol into p-aminophenol.

\section{Results and Discussion}

Characteristics of catalysts

$X$-ray diffraction $(X R D)$

XRD analysis used to follow up the change in the crystallinity of $\mathrm{Ni}$ metal before and after the reaction.

Figures 3,4 show XRD for Ni without support. They show that a change in the crystallinity of nickel occurs after the reduction of p-nitro phenol

Figures 5,6 show the XRD for Ni-faujasite catalyst before and after conducting the reaction of reduction of p-nitrophenol. As we see from these figures, the participation of the catalyst in the reaction decreases considerably the crystallinity of metallic nickel and also slightly decreases the crystallinity of zeolite.

\section{Scanning electron microscopic (SEM)}

The reduced nano-metallic nickel is widely distributed as seen in Fig.7. After reaction, the reduced nanonickel particles are agglomerated (Fig. 8) leading to less exposed surface nanonickel for further reaction and consequently the reactivity of the catalyst is quickly decreased.

Figure 9 shows the zeolite containing nano nickel. From this figure, it can be seen that the nano nickel is widely distributed on the surface of zeolite.

Figure 10 illustrates the SEM-image of the distributed nanonickel on zeolite surface. It is clear that the presence of zeolite prevents to a large extent the agglomeration of nano nickel leaving it widely distributed on the zeolite surface and consequently the catalyst appeared durability and activity higher than the unsupported one.

Reduction of p-nitrophenol using different weights of $\mathrm{Ni}\left(\mathrm{NO}_{3}\right)_{2} .6 \mathrm{H}_{2} \mathrm{O}$ (unsupported $\mathrm{Ni}$ )

The first step of the process was conducted by reduction of $0.123,0.247$ and $0.495 \mathrm{gm}$ of $\mathrm{Ni}\left(\mathrm{NO}_{3}\right)_{2} .6 \mathrm{H}_{2} \mathrm{O}$ which equivalent to $2.5,5$ and $10 \% \mathrm{Ni}$ in case of supported catalysts. The second step was a series of reduction of different doses of p-nitrophenol each of $5 \mathrm{ml}$ solution $(12.5 \mathrm{gm}$ in $50 \mathrm{ml}$ methanol). The results are represented in Fig. 11

From Fig. 11, it can be seen that the increase of nickel content was accompanied by the decrease in the time taken for complete reduction of the $5 \mathrm{ml} \mathrm{p}$-nitrophenol solution. In the same time the increase of the weight of nickel catalyst increases the possibility for more reduction of p-nitrophenol i.e .increase the number of additions of p-nitrophenol.

Reduction of p-nitrophenol by different weights of catalysts containing $2.5 \% \mathrm{Ni}$ - loaded on faujasiteZeolite

In this series of experiments the reduction of p-nitrophenol was performed on different weights of catalysts containing $2.5 \%$ nickel on zeolite. 


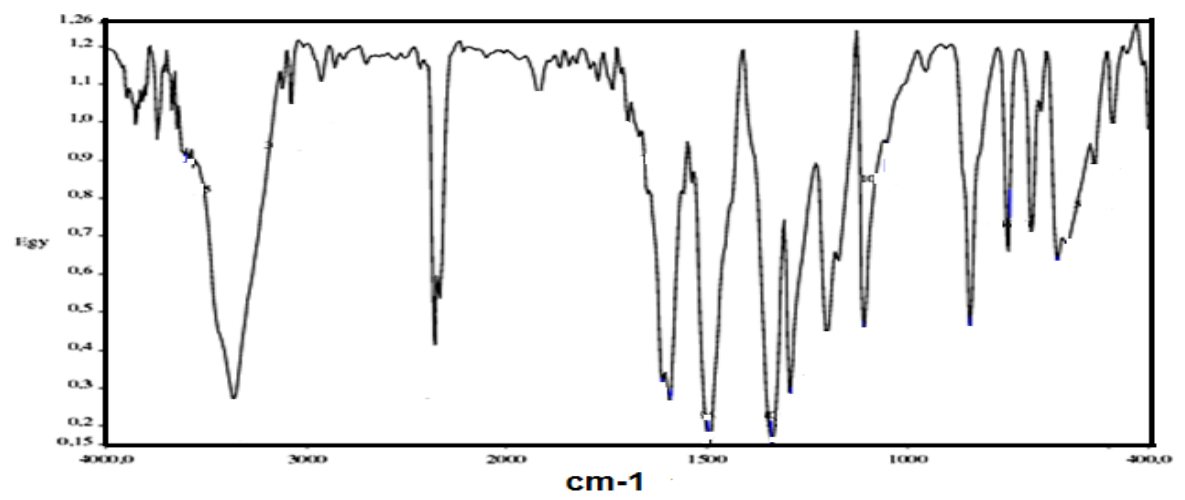

Fig. 1. FTIR-p-nitrophenol.

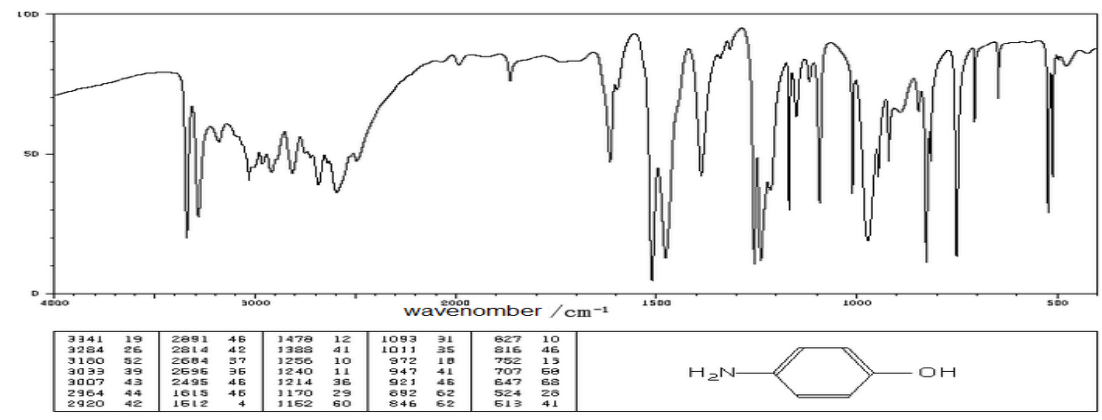

Fig. 2. FTIR-p-aminophenol.

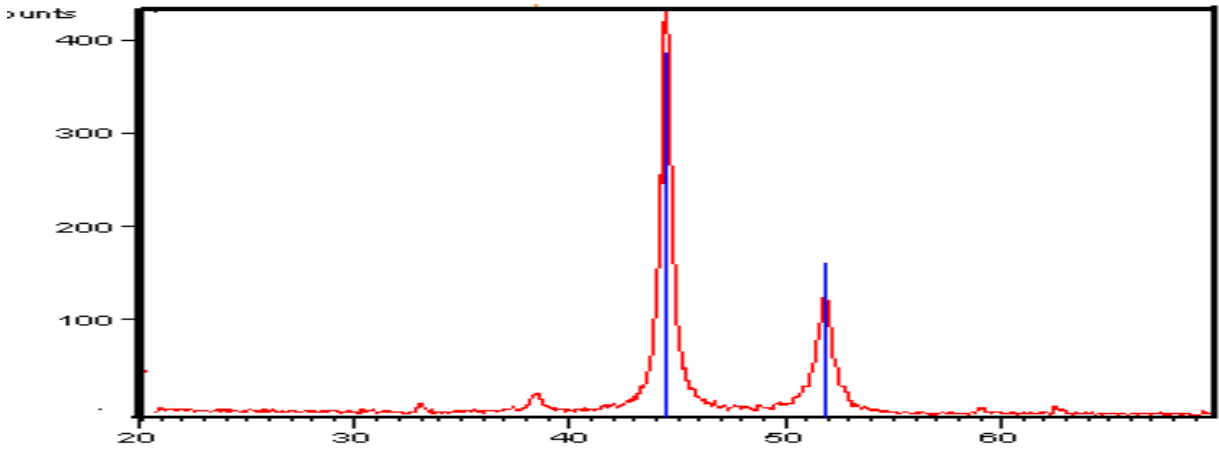

Fig. 3. XRD of Ni before the reaction.

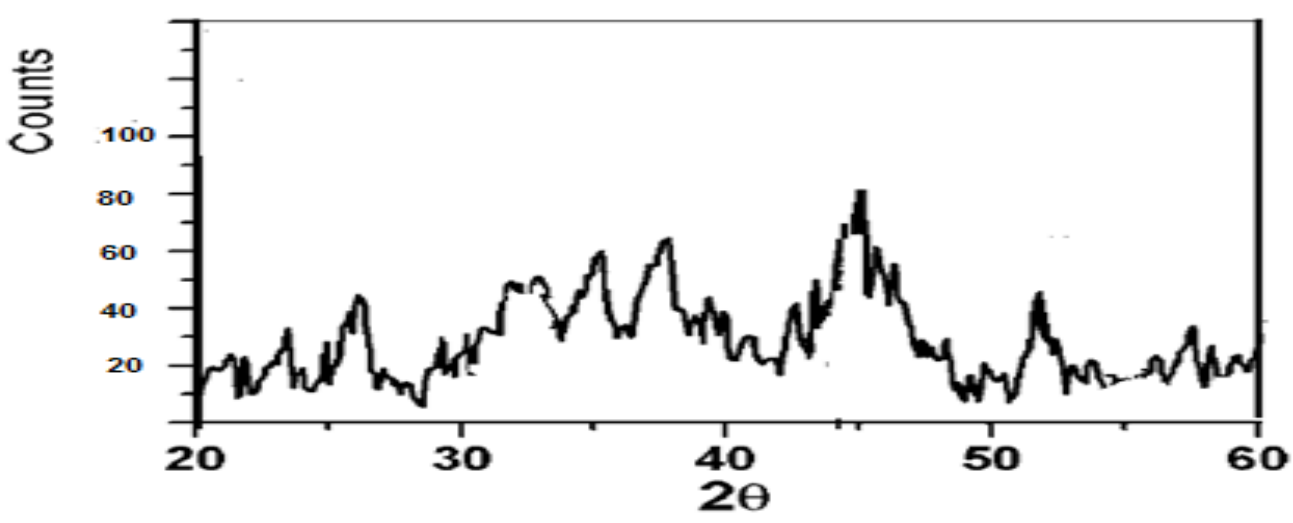

Fig. 4. XRD of Ni after the reaction. 


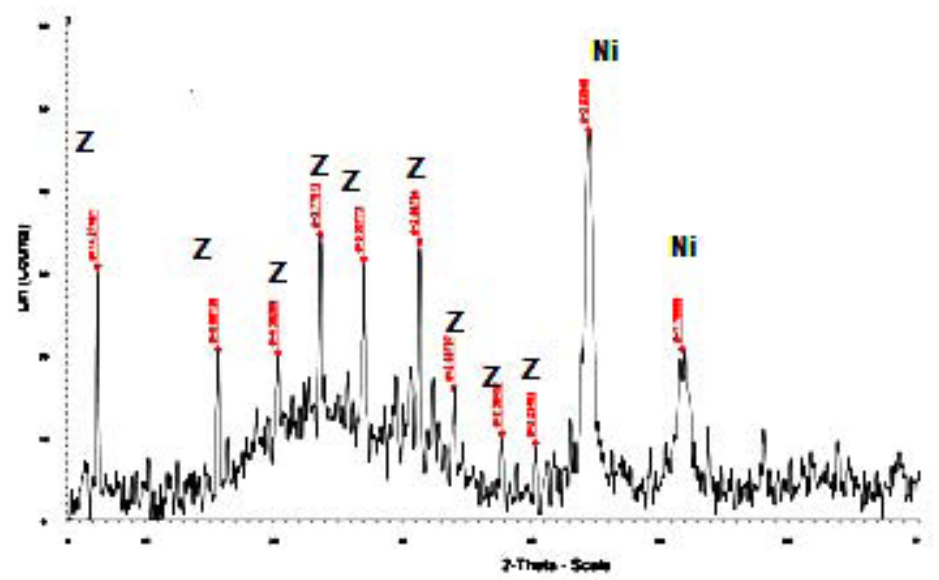

Fig. 5. SEM- unsupported Ni before reduction of p- nitrophenol

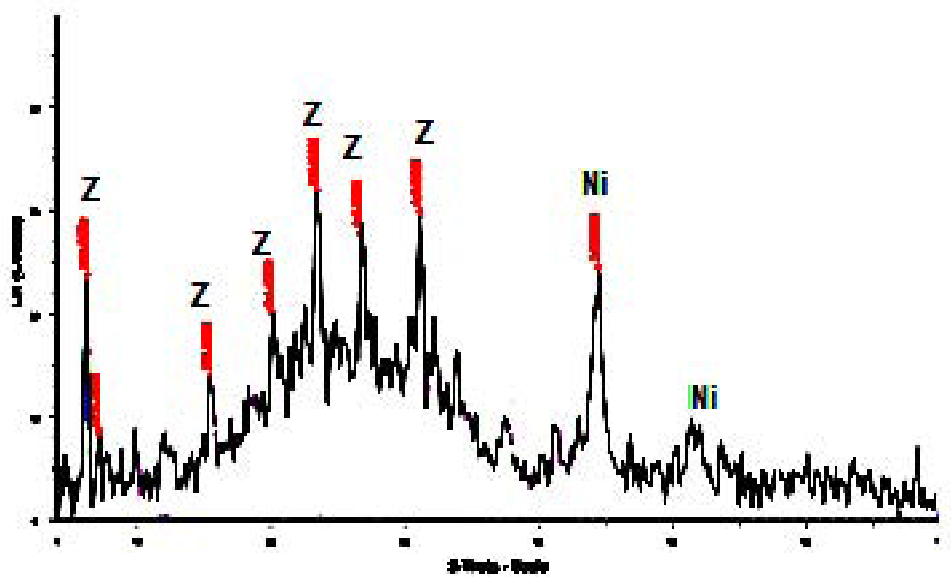

Fig. 6. SEM -unsupported Ni after reduction of p-nitrophenol

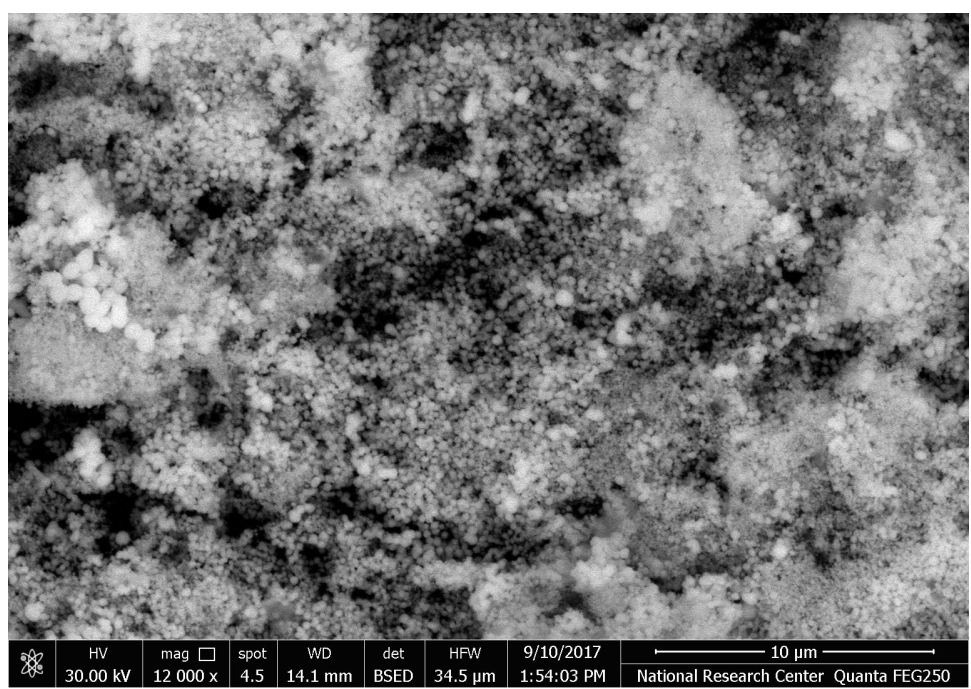

Fig. 7. SEM- unsupported Ni before reduction of p- nitrophenol. 


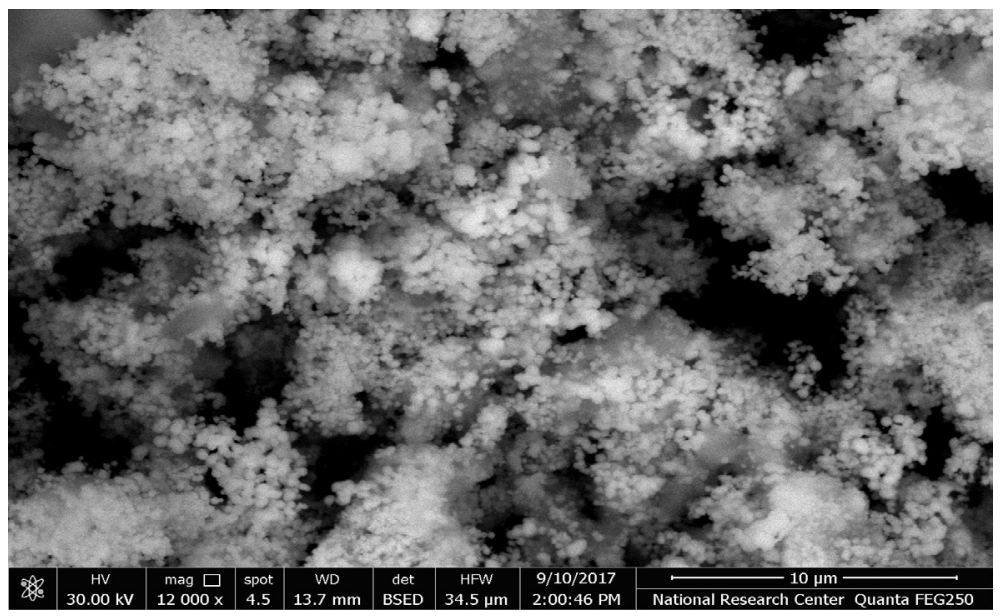

Fig. 8. SEM -unsupported Ni after reduction of p-nitrophenol.

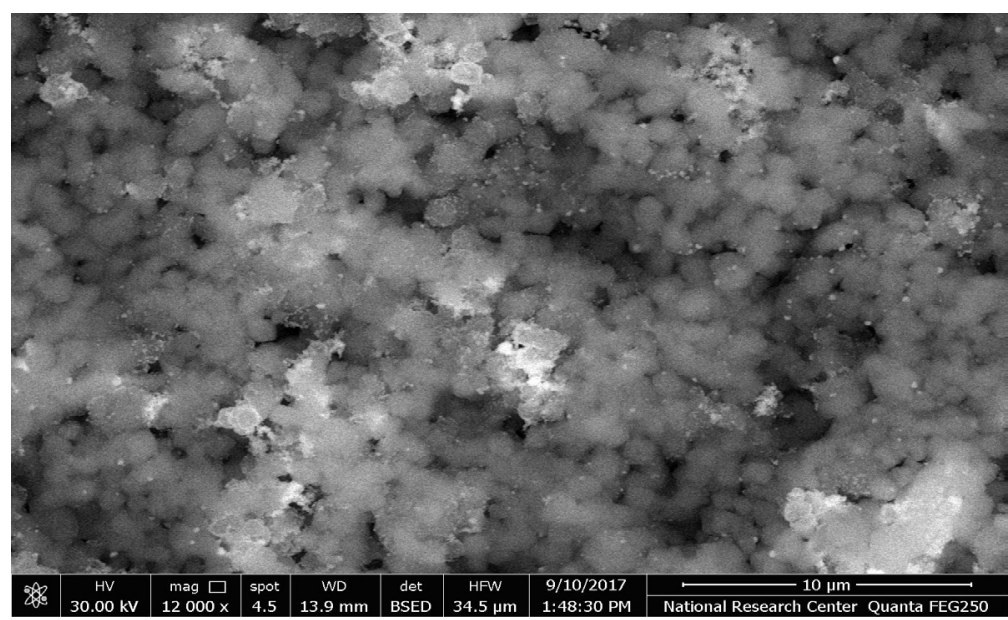

Fig. 9. SEM - Ni/ Zeolite before reduction of p-nitrophenol.

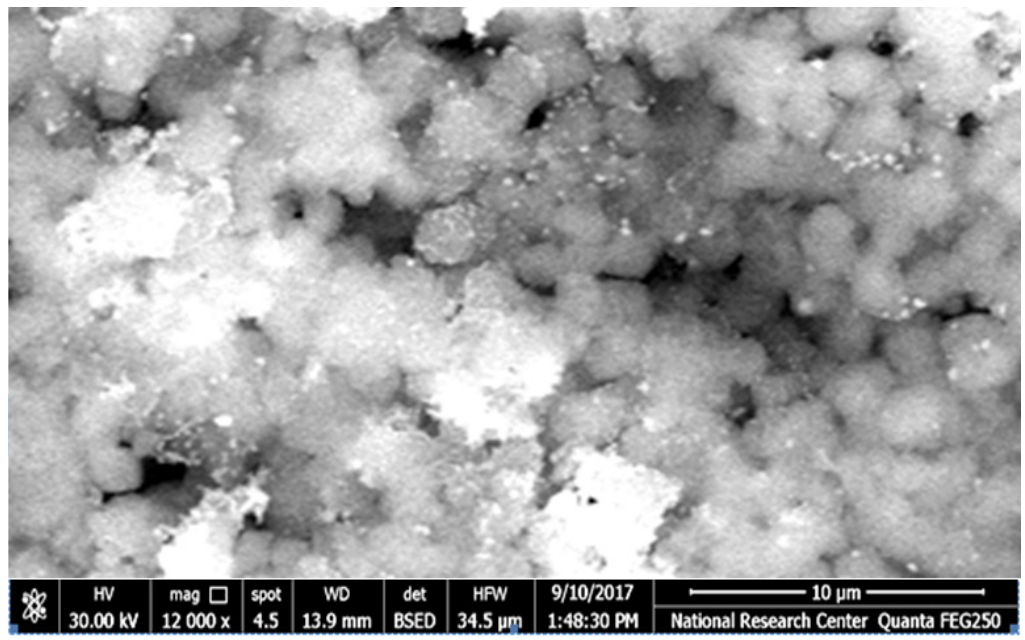

Fig. 10. SEM- Ni/ Zeolite after reduction of p-nitro phenol.

Egypt. J. Chem. 61, No.6 (2018) 


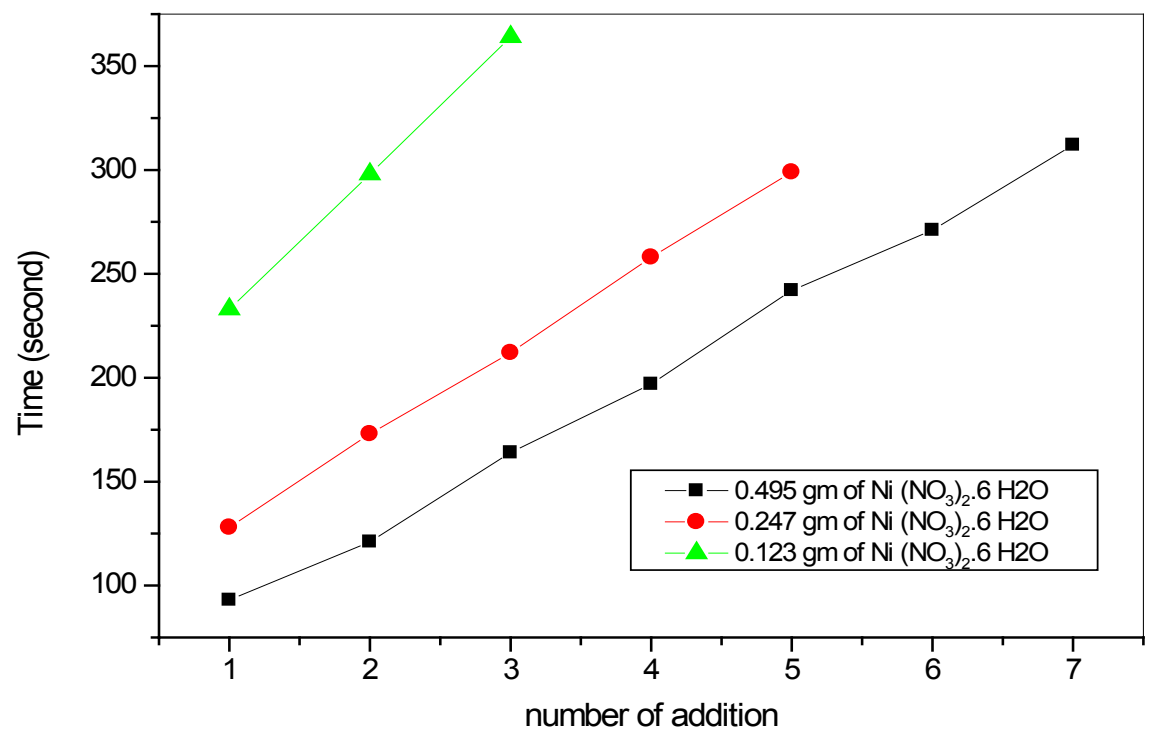

Fig. 11. The relation between the no. of additions of p-nitrophenol and time taken for reduction of p-nitrophenol.

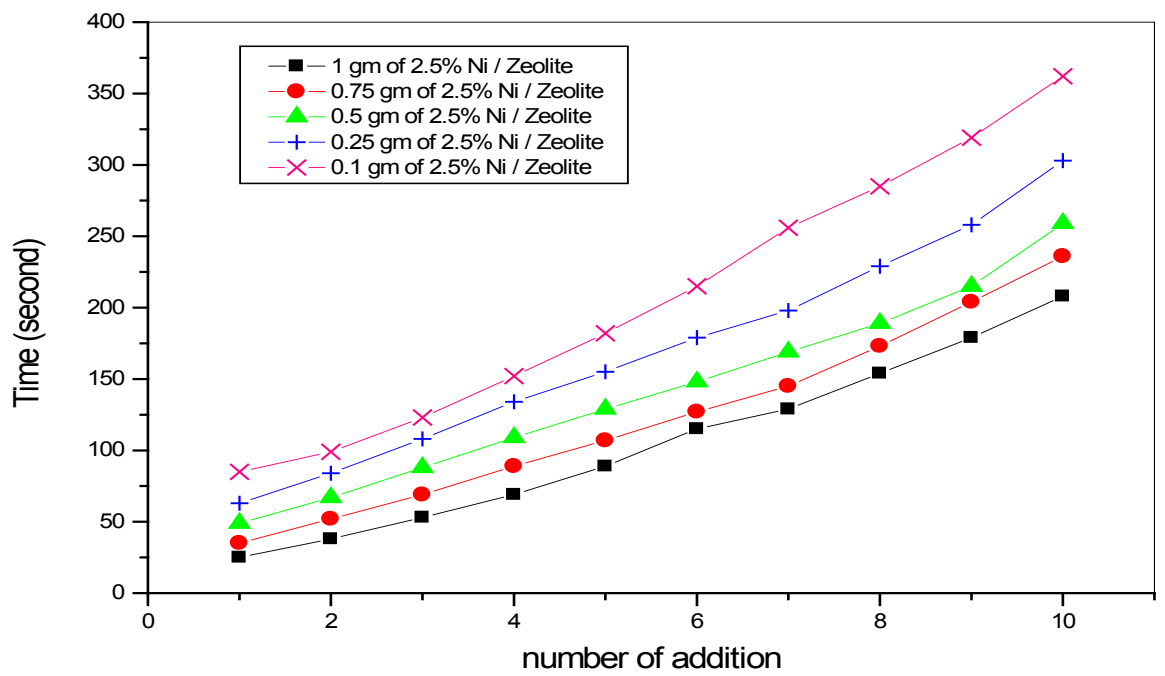

Fig. 12. Reduction of p-nitrophenol by different weights of catalysts containing $2.5 \% \mathrm{Ni}$ - loaded on faujasite-Zeolite.

The results of this series are illustrated in Fig.12. From these data it can be seen that the increae of catalyst weight increases the conversion of p-nitrophenol into p-aminophenol.

Reduction of p-nitrophenol by different weights of catalysts containning $5 \% \mathrm{Ni}$ - loaded on faujasiteZeolite

In this series of experiments the reduction of p-nitrophenol was performed on different weights of catalysts containing $5 \%$ nickel on zeolite.
The results of this series are illustrated in Fig.13. From these data, it can be seen that the increase of catalyst weight increases the conversion of p-nitrophenol into p-aminophenol.

Reduction of p-nitrophenol by different weights of catalysts containing $10 \% \mathrm{Ni}$-loaded on faujasiteZeolite

In this series of experiments, the reduction of p-nitrophenol was performed on different weights of catalysts containing $10 \%$ nickel on zeolite. 


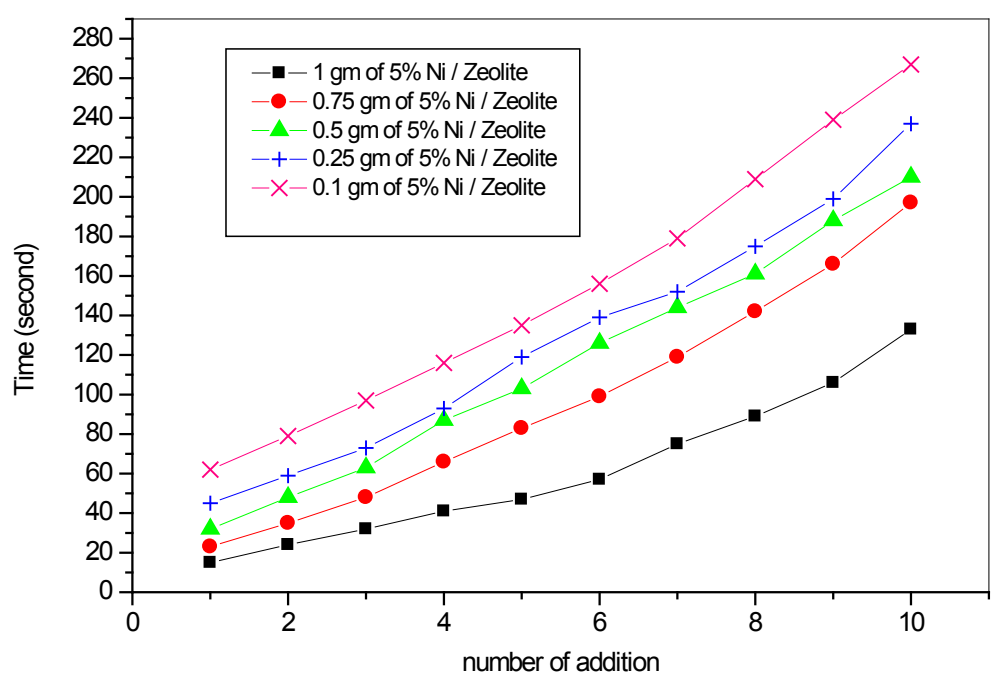

Fig. 13. Reduction of p-nitrophenol by different weights of catalysts containing $5 \% \mathrm{Ni}$ - loaded on faujasite-Zeolite

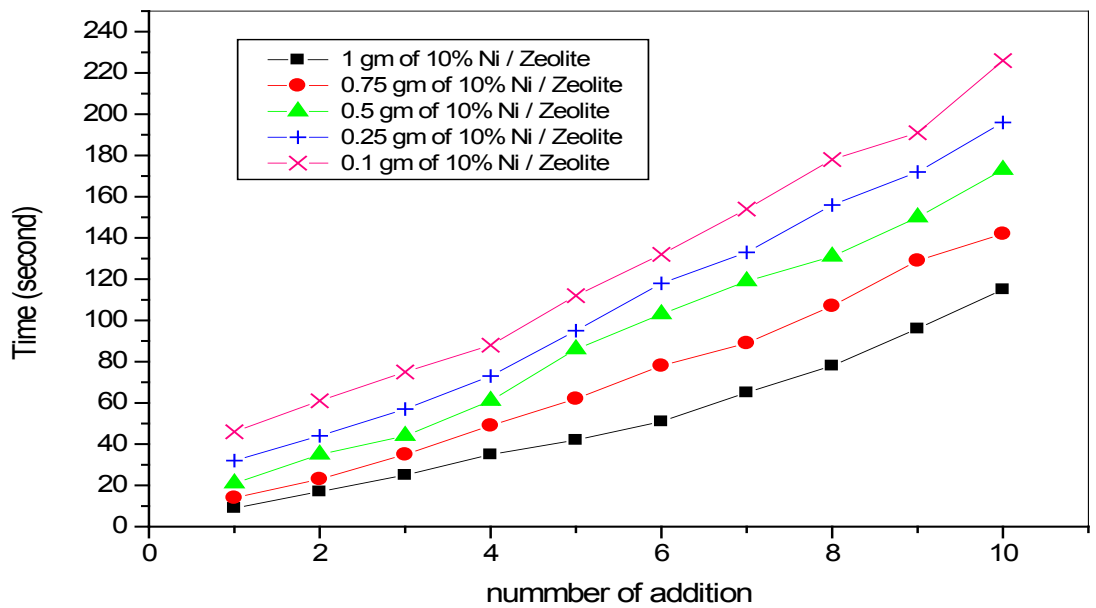

Fig.14. Reduction of p-nitrophenol by different weights of catalysts containing $5 \% \mathrm{Ni}$ - loaded on faujasite-Zeolite

The results of this series are illustrated in Fig.14. From these data, it can be seen that the increase of catalyst weight increases the conversion of p-nitrophenol into p-aminophenol.

Figure 14 Reduction of p-nitrophenol by different weights of catalysts containing $5 \% \mathrm{Ni}-$ loaded on faujasite-Zeolite.
The mechanism of reduction by hydrazine

The decomposition of hydrazine by nano nickel produces hydrogen which combined with the nitrogroup of para-nitrophenol(yellow) followed by elimination of two molecules of water and rearrangement of the molecule forming a green intermediate. The green intermediate is combined with hydrogen forming $\mathrm{p}$-aminophenol(colorless). This process is clearly illustrated in the following scheme. 


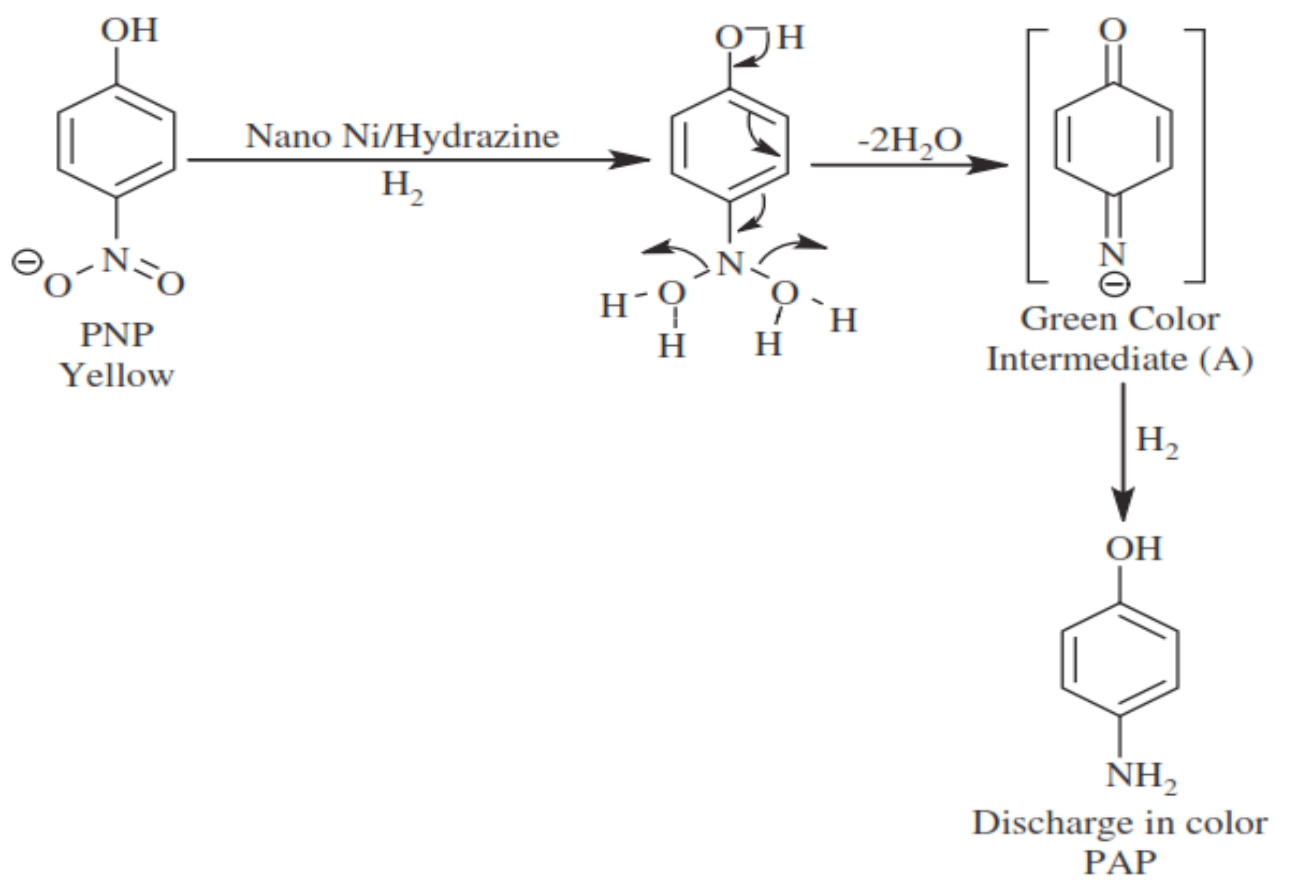

Supposed mechanism for reduction process of p-nitrophenol (17).

\section{Conclusions}

The removal of p-nitrophenol is considered as an important process especially if the conversion produces a useful material. The present work is dedicated to studying the conversion of p-nitrophenol into p-aminophenol (as useful pharmaceutical reagent). The conversion was performed catalytically on nano nickel. The supporting of nano nickel on zeolite increased considerably the activity of the used catalyst.

\section{References}

1. Schrinner M., Ballauff M., Talmon Y., Kauffmann Y., Thun J., Möller M., Breu J., Single nanocrystals of platinum prepared by partial dissolution of AuPt-nanoalloys, Science 323, 617 (2009).

2. Nolte P., Stierle A., Kasper N., Schulli T.U.and Dosch H.. Shape Changes of Supported Rh Nanoparticles during Oxidation and Reduction Cycles, Science 321, 1654 (2008).

3. Tian N., Zhou Z.Y., Sun S.G., Ding Y., Wang Z.L., Synthesis of tetrahexahedral platinum nano crystals with high-index facets and high electrooxidation activity, Science 316, 732 (2007).

4. Telkar M., Rodea C., Chaudhari R., Joshi S., Nalawade A., Shape-controlled preparation and catalytic activity of metal nanoparticles for hydrogenation of 2-butyne-1, 4-diol and styrene oxide. Appl.Catal.A: Gen 273, 11 (2004).

5. Liu Y., Chen Y., Hydrogenation of pChloronitrobenzene on Lanthanum- Promoted NiBNanometal Catalysts, Ind. Eng. Chem.Res. 45, 2973 (2006).

6. Vaidya M., Kulkarni S., Chaudhari R., Synthesis of p-Aminophenol by Catalytic Hydrogenation of p-Nitrophenol Org. Process Res. Dev. 7, 202 (2003).

7. Hutchings G., Nanoparticles and Catalysis, Catal. Today 100, 55 (2005).

8. Chen Z., Pina C., Falletta E., Faro M., Pasta M., Rossi M., Santo N., Fuel cell performance and characterization of 1-D carbon-supported platinum nanocomposites synthesized in supercritical fluids, J.Catal.259, 1 (2008).

9. Yu D., Yam V., Metallic Nanostructures: From Controlled Synthesis to Applications, J.Phys. Chem. B 109, 5497 (2006).

10. Rashid M., Mandal T., Nanostructured Materials, Preparation via Condensation Ways, J.Phys.Chem. C 111, 16750 (2007).

11. Lu H., Yin H., Liu Y., Jiang T., Yu L., Trends in Asian Water Environmental Science and Technology, Catal. Commun.10, 313 (2008). 
12. Du Y., Chen H., Xu N., Application of $\mathrm{NiCo}_{2} \mathrm{O}_{4}$ as a catalyst in the conversion of p-nitrophenol to p-aminophenol, Appl. Xu, Appl. Catal.A: Gen. 277, 259 (2004).

13. Chen R., Wang Q., Du Y., Xing W., Xu N., Effect of initial solution apparent $\mathrm{pH}$ on nano-sized nickel catalysts in $p$-nitrophenol hydrogenation Chem.Eng.J. 145, 371 (2009).

14. Payra P., Dutta P. K., Handbook of Zeolite Science and Technology, Dekker, New York, 1-19 (2004).

15. Fisher K., Huddersman K., Taylor M., Comparison of Micro- and Mesoporous Inorganic Materials in the Uptake and Release of the Drug Model Fluorescein and Its Analogues. Chem. Eur. J, 9, 5873-5878 (2003).
16. Pinza M., Brufani M., Milanese C., Use of $\mathrm{p}$-aminophenol derivatives for the preparation of pharmaceutical compositions useful in the treatment of neurodegenerative diseases, US Patent 6043285 (2000).

17. Selim M., Abd El Maksod I., Saleh T., The use of nano supported nickel catalyst in reduction of p-nitrophenol using hydrazine hydrate as hydrogen donor. Egyptian Journal of Chemistry 52, 4,491 (2009).
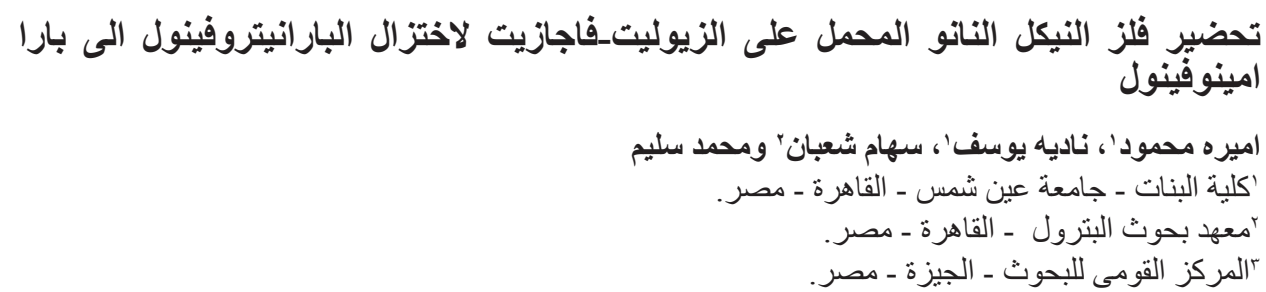

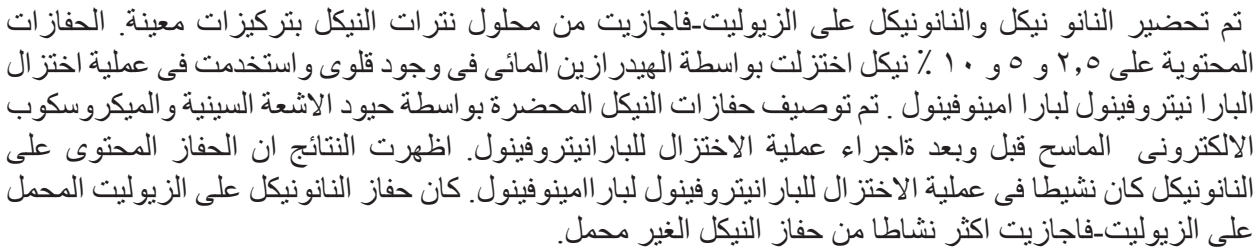

